\title{
A porous humanitarian shield: The laws of war, the red cross, and the killing of civilians
}

\author{
Margit Bussmann $^{1} \cdot$ Gerald Schneider $^{2}$
}

\begin{abstract}
An important literature examines the attempts by the international community in inducing or coercing conflict parties in civil wars to refrain from committing atrocities against the civilian population. We examine in this article whether a nongovernmental actor, the distinctively neutral and independent International Committee of the Red Cross, whose mission includes the promotion of humanitarian law and the protection of the civilian population, has such a restraining effect on the conflict parties. Our results suggest that the more time has passed since the ratification of the relevant Geneva Conventions and Protocols, the larger is the risk of civilian victimization. We cannot find evidence that the ICRC's presence in conflict zones and the seminars it conducts to spread humanitarian law make a crucial difference. Case studies of Bosnia and Darfur indicate that shaming strategies and thus a relatively unusual instrument for the traditionally neutral actor did not abate the killings; the statistical evidence in the form of Granger causality tests rather show that the killing and harming precedes the naming and shaming.
\end{abstract}

Keywords Civil war-Laws of war-Geneva conventions - International Committee of the Red Cross · One-sided violence $\cdot$ Compliance

$\mathrm{JEL} \cdot \mathrm{D} 74 \cdot \mathrm{K} 33 \cdot \mathrm{K} 42 \cdot \mathrm{F} 52$

Gerald Schneider

Gerald.Schneider@uni konstanz.de

Margit Bussmann

Margit.Bussmann@uni greifswald.de

1 Department of Political Science and Communications, University of Greifswald, Baderstr. 6/7, 17489 Greifswald, Germany

2 Department of Politics and Public Administration and Graduate School of Decision Sciences, University of Konstanz, Box 86, 78457 Constance, Germany 


\section{Introduction}

Scholars studying violent conflict analyze the behavior of a variety of actors in war-torn societies. Besides the conflict parties and third party states, an important role is ascribed to international organizations. Whereas governmental organizations, like the United Nations, receive widespread scholarly attention, non-governmental organizations are often not in the limelight of academic research and are mostly attributed a role in postconflict reconstruction. Indeed, few international organizations are systematically present in conflict zones. One of the few exceptions is the International Committee of the Red Cross (ICRC). Its main tasks are to visit detainees, to provide assistance for conflict victims, such as health services, and survival relief, but also to prevent and contain harmful effects of conflict by promoting international humanitarian law.

The ICRC sees itself as an "impartial, neutral and independent organization whose exclusively humanitarian mission is to protect the lives and dignity of victims of armed conflict and other situations of violence and to provide them with assistance." ${ }^{1}$ This article examines whether the ICRC reaches the objective to promote respect for international humanitarian law (IHL) and whether it is sufficiently present in those states around the world in which one of the key goals of the Law of War, the protection of civilians, is particularly endangered.

The ICRC has played the leading role in the development of IHL and is widely accepted to be its watchdog (Forsythe 2005). The first Geneva Convention, which was drafted by a group of private individuals around the founder of the ICRC, Henry Dunant, was signed by 14 European states in 1864 . Although this and the subsequent conventions attributed the main responsibility for the implementation of these rules to the ratifying member states, the ICRC indirectly became the main international guardian of the Law of War besides the League of Nations and the United Nations. ${ }^{2}$ To prevent IHL violations and to protect civilians, the ICRC engages into dialogue with the national authorities as well as with state and non-state armed actors and, among other (frequently confidential) activities, conducts seminars to persuade members of the armed forces not to attack and mistreat civilians and military personnel hors de combat. According to the annual report of 2008, the ICRC had 30 specialized delegates for this purpose and sponsors courses for military officers in the International Institute in San Remo (ICRC 2009).

While the ICRC has already received the Nobel Peace Prize three times, in addition to the one awarded to Henry Dunant, ${ }^{3}$ various theories of international relations suggest that the influence of non-state actors like the Geneva-based organization on real or potential human rights abusers remains limited at best and might, in some cases, even

\footnotetext{
${ }^{1}$ Mission statement available on the ICRC website: http://www.icrc.org/HOME.NSF/ 060a34982cae624ec12566fe00326312/125ffe2d4c7f68acc1256ae300394f6e?OpenDocument (July 18, 2013).

${ }^{2}$ Subsequent landmark developments in the evolution of the Law of War include the Geneva conventions of 1906, 1929, and 1949 as well as the The Hague $(1899,1907)$ conventions. Three protocols, which date from 1977 and 2005 respectively, have amended the 1949 Geneva Convention and have led to stronger legal protection of civilian victims of war.

${ }^{3}$ Whether the ICRC is a strictly private or a hybrid international organization is subject to discussion (see Forsythe 2005). Although largely supported by states, since only individuals of Swiss nationality and not states are members with voting rights in the Assembly, the ICRC's main governing body, we refer to it as a non-governmental organization.
} 
be counterproductive. A growing literature indicates, however, that the activities of non-governmental international actors are much more positive than the realist thesis that such interventions remain epiphenomenal in a wider context lets us expect. Shaming efforts by international human rights NGOs can accordingly limit civilian killings (DeMeritt 2012, Krain 2012) and trigger humanitarian interventions (Murdie and Peksen 2014). We add to these encouraging findings an evaluation of the norms and activities of the IRC. Mainly legal or historical studies of this NGO have appeared so far but few social scientists have closely examined the genesis and functioning of the ICRC (Finnemore 1996, chap.3; Forsythe 2005).

This article pursues a different research agenda and examines the extent to which the main actors in civil wars - governments and rebel groups - comply with the international norm to protect civilians advocated by the ICRC. Formal work suggests that institutions like the ICRC which do not possess a powerful enforcement mechanism can deter atrocities to some limited extent. We particularly expect, in line with the work of Michael Gilligan (2006), that compliance success of the Geneva organization will vary with the perpetrator's anticipated opportunity costs of ordering the killing and maiming of civilians. These costs will be higher for government than for rebel leaders. Although the Law of War extends to all conflict parties, governments are the signatories of the international agreement and therefore primarily liable for gross violations of the international norms. If they target civilians in a blatant way, they face the risk of international isolation and of economic or political sanctions. The opportunity cost argument that we propose suggests that the costs of a signature will decline over time and that the longer a country participates in the Law of War regime, the lower should be the inhibition to target civilians. Once a conflict has escalated, the ICRC could overcome this treaty inheritance problem through attempts to socialize combatants into these norms or through the usage of soft coercive measures like condemnations (Finnemore 1993; Hafner-Burton 2008). In this article, we will examine whether the seminars it conducts help in persuading potential perpetrators to stop the victimization of civilians and whether the naming and shaming of these actors through the rare and therefore highly targeted ICRC statements has a similarly positive effect.

Making usage of data sets on violence against civilians, ${ }^{4}$ we analyze whether the presence of the ICRC limits the killing and harming of civilians in conflicts around the world. Our regression models show that the ICRC's activities in this realm are not related to less abuse of civilians, especially killings by rebel groups. This result challenges the hope of the ICRC that domestic actors become socialized over time with the Law of War and learn to act more humanely in conflict situations. The physical presence of the ICRC is not associated with less extensive civilian abuse. Our statistical analysis shows that proactive policies like seminars for military personnel and the warning or condemnation of the warring parties do not correlate with less violence against civilians either. We examine the hypothesis of the potential harm-reducing effect of the strategy of naming and shaming with the help of more fine-grained time series of the ups and downs of one-sided violence in two conflicts in which the ICRC

\footnotetext{
${ }^{4}$ Schneider and Bussmann (2013: 635), based on Eck and Hultman (2007) define one-sided violence as "lethal or harmful acts that an organized group, which can be either a rebel organization or government actors, directs against unarmed individuals. The aggression results in the immediate physical harming or death of more than one person."
} 
frequently intervened through public diplomacy. The analyses show for the conflicts in Bosnia and Darfur that the public condemnations have a negligible effect on the atrocities committed in these conflicts and that one-sided violence precedes in the sense of Granger causality the ICRC statements. The reactive way in which the ICRC has responded to these crises and the general limitations of the humanitarian regime suggest that the Geneva-based organization should reconsider the strategies that it uses for the protection of the civilians in crisis-ridden regions.

\section{The neutrality of humanitarian interventions}

There are various approaches that try to explain why we can observe more or less onesided violence in wars. Explanations range from strategic considerations and the balance of power of the conflict parties to factors that relate to the internal organization and sanctioning mechanisms of the perpetrating forces (Downes 2008; Kalyvas 2006; Weinstein 2007). Another strand of literature blames the international community, or rather its absence in conflict areas, for the atrocities against the civilian population in times of armed conflict. Valentino (2004), for example, advances the view that international actors by means of military intervention can limit or even prevent the occurrence of mass killings during wars (see also Krain 2005).

The effectiveness of such interventions is heavily disputed, and the question of whether a neutral actor reduces the carnage or not has preoccupied conflict researchers since decades. Most early studies on this topic boiled down to the contention that impartiality is a key for successful interventions and effective conflict management. Young (1967: 81) is one of many who claim in this vein that "a high score in such areas as impartiality would seem to be at the heart of successful interventions in many situations." However, recent theoretical and empirical advances show that the nexus between the impartiality of an intervention and its effectiveness is much more involved; these studies explicitly or implicitly question the endogeneity of neutrality and treat impartiality as a means to compensate for a lack of power. Some contributions on the effectiveness of peacekeeping missions suggest that impartial interventions of the international community may have adverse effects on the civilian populations. Krain's (2005) study of the genocides between 1955 and 1997 indicates that only partial and militarily bolstered interventions enable the international community to shelter the civilian population against the malign intentions of the perpetrators and to dampen mass-killings. The UN peacekeepers' effective contribution to the protection of civilians depends crucially on whether they have a respective mandate (Hultman 2010) and the mission needs to be sufficiently staffed with military and police forces (Hultman et al. 2013).

This suggests that "simply sending troops without the mandate to interfere when necessary can be devastating"(Hultman 2010: 42). However, case study evidence suggests that even explicit mandates can have counter-productive effects. Branch (2009) for instance contends, based on a study of Uganda, that "humanitarianism can be instrumentalised by $[\ldots]$ warring parties for their own end, leading to a prolongation of the very violence it purports to ameliorate" (479). Moreover, conflict management by formally neutral mediators is less effective than other state-led mediations as neutral 
mediators often agree to intervene in relatively hopeless cases and neutral mediations are less informative (Bercovitch and Schneider 2000; Kydd 2003).

Although the impact of neutrality in conflict management is disputed, the ICRC and some of its analysts continue to see it as a key principle for its worldwide activities $(\mathrm{Ku}$ and Brun 2003). Such portrayals can, however, not mask that the impartiality of several missions has been fiercely debated. Former ICRC delegate Balmer (1984) described the difficulties the organization had in remaining neutral during the civil war in El Salvador, accusing key representatives of the organization of colluding with the interest of the United States. Forsythe (2005) does not only highlight various examples where the ICRC did not have a very neutral stand (e.g., Italy in Ethiopia), or points to the close connection between the ICRC and the Swiss government in the past, but also summarizes the criticism that is related to the refusal of the ICRC to publicly speak out against severe violations of humanitarian law and thus to engage into the practice of naming and shaming. He maintains that the ICRC's tradition of discretion might have been counter-productive in some cases. Cases in point are the silence of the organization with regard to the Holocaust (Favez 1988) or, in case of its implementation in Hungary, its tardiness in trying to rescue the Jewish population from the Nazi and Arrow Cross henchmen (Ben-Tov 1990). According to a former President of the ICRC, speaking out for the European Jews would have not been effective as "such an appeal could lead to a loss of access to some two million Allied prisoners of war whom the ICRC was then assisting" (Kellenberger 2004: 598). As acts of one-sided violence, by their gruesome nature, demand partial actions, it is not surprising that the ICRC has loosened its policy of discretion and neutrality. In the view of Delorenzi (1999: 28-29), the organization has started to strike "a balance between discretion and public condemnation" following the usage of poisonous gas in Yemen in 1967. However, the ICRC is far from relying on public condemnations as frequently as similar organizations like Médecins Sans Frontières or Amnesty International. ${ }^{5}$ Some of these NGOs were partly founded in response to the perceived impossibility that an international actor like the ICRC remains neutral and discrete in a conflict like the war in Biafra with its monstrous mass killings.

\section{Theoretical arguments}

A growing number of studies examines the compliance with and effectiveness of the international norms for the protection of life integrity rights; these investigations are, however, equally inconclusive as the related studies on peacekeeping. Domestic political and legal enforcement of treaties as well as collateral consequences of noncompliance influence the decision of whether or not a government lives up to the obligations of such treaties (Hathaway 2007). Simmons (2009) forcefully contends that the international commitments such treaties entail have improved the human rights records of signatory states. Hafner-Burton and Tsutsui (2007), by contrast, argue that

\footnotetext{
${ }^{5}$ To protect its delegates, the organization refrained from calling the killings in Rwanda "genocide." Former president Kellenberger (2004: 602) nevertheless insists that the ICRC acted decisively: "It would be hard to conceive of a more dramatic and urgent public appeal to the international community than that of 28 April 1994."
} 
the international human rights regime serves as a symbol for the "paradox of empty promises" (1378). Hence, although governments sign and ratify international human rights treaties, they do not necessarily comply with them.

The level of democracy as well as the number of citizens participating in NGOs rather than the ratification of an international treaty improves the human rights record of a state. Yet, while the human rights regime may not be directly effective, it may at least propel states to respect these norms indirectly through the conclusion of preferential trade agreements that include a human rights clause (Neumayer 2005). HafnerBurton (2005: 595) observes that such agreements typically include strong enforcement mechanisms. This should, in her view, increase the chance that a government respects the human rights of its citizens. However, she admits later that governments which have signed such agreements still often do not implement the human rights clauses (HafnerBurton 2009).

The compliance of governments with the Law of War has been studied by Morrow (2007, 2014). His statistical analysis of international conflicts suggests that the rules that protect civilians during warfare have the poorest compliance record, while other rules such as the ones banning the usage of chemical or biological weapons are much more closely observed. Compliance and non-compliance with the Law of War has furthermore a strong reciprocal nature in interstate conflicts: "When one side does not comply, the other responds in kind, and joint ratification strengthens reciprocal enforcements" (2007: 570). The international norms advocated by the ICRC strengthen, in his view, this enforcement and prevent the international treaties to be just toothless tigers.

The ICRC's influence in promoting and controlling IHL in internal wars is, however, much weaker. A core problem is that non-state armed groups are not signatories of the agreement. A study by Jo and Thomson (2014) on the international norm to grant the ICRC access to prisoners of war did not provide evidence of reciprocity in compliant behavior of conflict parties in intra-state wars. Whether non-state actors comply depends largely, as it does for government actors, on whether they strive for legitimacy. Rebel groups that have a political wing and that can rely on domestic or external support are more likely to allow the ICRC to conduct visits in its detention centers.

Some research moreover suggests that compliance with IHL is not static and will change with time. According to the constructivist perspective, two key mechanisms, learning and socialization, render international norms more effective over time. As Finnemore and Sikkink (1998: 902) argue, norms evolve in a "life cycle," passing through stages of evolution, acceptance, and internalization. They see in this way the ICRC as the "chief socializing agent" of the Geneva Conventions. Increasing compliance can also result from a sequential growth in the severity of the treaty obligations: "human rights regimes can potentially employ coercive techniques most effectively once robust levels of internalization have occurred" (Goodman and Jinks 2004: 702).

Although this logic might prevail for some international norms, compliance with a high-stake regulatory framework like the Laws of War might in our view decline with the passage of time. This challenge to international humanitarian law becomes apparent through a combination of the literatures on time inconsistency and regime effectiveness. The time inconsistency problem suggests that the utility of a specific decision is dependent on time. What appears ideal today for the signatory government might be suboptimal tomorrow in the perspective of its successor. This means that the passage of 
time enables successor governments to argue and act against an international obligation although they are legally still constrained by it (Kydland and Prescott 1977). Simmons (2010: 276-277) shows in support of this conjecture that compliance with international norms decreases over time if the ratifying states cannot credibly commit to observe the treaty obligations in the long-term. If actors can repeatedly observe that violations against the treaty by others are not severely punished, their inclination to be respectful of the ratified obligations will also decline as time passes. The literature on regime effectiveness similarly suggests that a humanitarian regime like the one created through the Law of War must remain shallow in the absence of a strong sanctioning mechanism. According to Gilligan's (2006) analysis of the International Criminal Court, some leaders will refrain from committing atrocities if there is even a remote chance that they will face a tribunal instead of going into asylum in a third state in case they lose power. ${ }^{6}$ In other words, the compliance of a regime, like the one guarded by the ICRC, will grow, the higher the opportunity costs of committing crimes against humanity. In the aftermath of a signature when there is widespread and prominent public attention on the issue at stake, these costs are relatively high, but they will fade out the more distant the ratification of an international regime is and the more the international public has forgotten that a specific country has ratified the norm at one point. Compliance with the Law of War becomes especially problematic when a government pledged its adherence to the treaty in a relatively peaceful period, but is unexpectedly challenged sometime later by rebel troops. Government and regime changes exacerbates this problem as succeeding generations of politicians feel less bound by the international obligations than the signatory governments. Given this treaty inheritance problem, we conjecture governments to observe the IHL on the protection of civilians less and less with the passage of time. Rebels are not signatories to international humanitarian law, thus we do not expect them to feel obliged to obey it in the first place.

The empirical record on whether compliance grows with the passage of time is rather ambiguous. Examining regional ratification patterns for various human rights regimes, Simmons (2009: 96) rejects the passage of time hypothesis according to which states are gradually converted to higher human rights standards. We therefore maintain that the power of the international norms will fade out over time due to the treaty inheritance problem.

H1: The longer ago a state has already ratified the relevant Geneva Convention and Protocol that oblige it to protect civilians in war, the more compliance will decline and more civilian victims can be observed.

Our study will go beyond the mere analysis of ratification of international humanitarian law by investigating whether the presence of the guardian of this body of international norms, the ICRC, makes any difference in preventing civilian casualties. Persuasion to follow international norms is only possible if the ICRC is present and able to communicate with the conflict parties directly. Case study evidence supports the view that the mere presence of the ICRC on the ground can help prevent the worst as this visibility increases for potential perpetrators the risk to be identified after an

\footnotetext{
${ }^{6}$ However, a study found no evidence that an international criminal tribunal or domestic human rights trials had any impact on the recurrence of civil war or a country's human rights record (Meernik et al. 2010).
} 
atrocity or reminds them of possible alternate routes of action. Such a mechanism was apparently at work during the genocide in Rwanda in 1994 at the Kamarampaka Stadium and Nayarushishi camp in Cyangugu where the International Red Cross was present, while the United Nations Assistance Mission for Rwanda (UNAMIR) were deployed at the Kabgayi Archbishopric in Gitarama prefecture and in the Amahoro stadium in Kigali city. As Kuperman (2001) notices, Hutu killers did not attack Tutsis and other opponents as openly at these locations as they did elsewhere: "Thus interestingly, it appears the modest deterrent impact of UNAMIR troops may have been more a function of their being foreign than their being armed, considering that the unarmed ICRC had a similar deterrent impact" (17). Whether the mere presence of a watchdog makes a difference can be questioned and needs to be studied in a wider context. If the ICRC is already present in a country for several years, it will have had more time to persuade potential perpetrators to respect the norms of IHL. However, if the conflict parties could observe in the past that the ICRC has no enforcement mechanisms at its disposal and violations of IHL remained without negative consequence; the willingness to obey the Law of War might decline.

This is presumably even stronger for the rebel side that is not a signatory to international law. Despite its neutrality the ICRC is more in contact with government officials than with rebel groups. Public authorities are its main partner in negotiating access to a country or detainees. In turn, government officials are to some extent interested in good relations with the large Geneva organization to get into its medical and emergency relief system. Rebel groups are frequently more remote and thus less restrained. The ICRC is aware of the problem that the Law of War does not necessarily reach the rebel forces although the rules are binding for all parties engaged in an internal war. Bugnion (2000) regrets in this context in an official ICRC publication "that there is no procedure that would allow the insurgent party to start respecting" (390; own translation) the second additional protocol of 1977 that extends the Geneva conventions to internal armed conflict. Although the protection of civilians is the pronounced goal of the ICRC and it invests considerable resources, we expect the ICRC's influence to be limited, for government forces but more importantly for rebel groups, and thus test explicitly the null hypothesis.

H2: The presence of the ICRC in a country does not make a difference to the number of civilians killed during civil war, in particular not for rebel groups.

The ICRC is active in conflict zones, thus the link between ICRC presence and the atrocities against civilians might reflect reverse causality. We would expect that the ICRC's staff is deployed to the most severe conflicts or to areas where the danger of massive violations of the humanitarian treaties looms largest. What is unclear, though, is whether the number of civilian victims has any decisive impact on deployment decisions. The direction of causality is problematic in particular with regard to the indicator variable of where the ICRC is currently present. In our sample, there are cases where the ICRC establishes a delegation with the outbreak of the present conflict, such as in Liberia. In other cases the ICRC is present in a country already for a long time (e.g., like in Egypt). The ICRC stays sometimes with a delegation or a regional delegation in a country even after the war has ended to attend to neighboring countries. Some conflicts simultaneously are so severe that ICRC and other organizations do 
either not send their teams there or scaled the missions down as a consequence of the increasing insecurity or the direct targeting of NGO workers (Fast 2007, 2010). The ICRC for instance reduced its personnel following the bombing of its Baghdad mission in 2003. In instrumental variable tests of robustness, we will address the question of whether reverse causality biases our findings and the ICRC's presence is influenced by one-sided violence.

Despite our general expectation that we can observe one-sided violence regardless of whether the ICRC is present in a country, we investigate if specific tools the ICRC uses prove to be effective. The literature on the compliance of international norms suggests, in the footsteps of Axelrod (1984), that the threat of sanctions is a key for the successful implementation of norms. As non-governmental actors like the ICRC lack the enforcement power of a state or an important IGO backed by powerful governments, they have to solve the treaty inheritance problem through other means. It is one of the most resourceful humanitarian actors on the globe ${ }^{7}$ and uses a variety of means to persuade armed forces that respecting the Law of War is in their very best interest. By taking a proactive stand the ICRC might be able to convince the conflict parties not to abuse and kill civilians.

We will in this respect distinguish between two instruments, persuasion and naming and shaming strategies. The seminars in which soldiers and commanders are exposed to the obligations that the ratification of IHL creates belong to the former category of instruments, while condemnations and warnings that the ICRC uses as a weapon of the last resort belong to the latter type of strategies. The former instrument is aimed at the values and beliefs of the actors who may be convinced by a good argument to refrain from using force. The ICRC possesses in the context of our study the possibility to persuade armed forces and their commanders from alternate courses mainly through its presence in conflict zones and through seminars it conducts. As part of its dissemination activities, the ICRC offers seminars on IHL to members of the armed forces in many countries affected by civil war with the goal to convince armed actors to obey the Law of War, among others that civilians and other unarmed individuals require special protection. These seminars sometimes address only military officers but often reach several thousand soldiers. Mostly government troops attend these sessions but the ICRC has also offered seminars to rebel groups. A broad literature expects that such strategies can be highly effective, especially if they come from actors like the ICRC. Particularly constructivist scholars attribute to non-governmental actors considerable power in convincing governments to respect life integrity rights through persuasion (Risse et al. 1999).

Naming and shaming, by contrast, follows a deterrent logic and tries to increase the opportunity costs of one-sided violence through soft sanctions such as public condemnations. Liberals believe the pressure that public diplomacy creates through condemnations of perpetrators effectively reduces the human suffering. According to Moravcsik (1995: 161) for instance, shaming "seeks to enforce individual human rights... by creating an international and domestic climate of opinion critical of national

\footnotetext{
${ }^{7}$ Médecins Sans Frontières for instance had a world-wide income in 2012 of $938 €$, while the ICRC had a similar income in contributions of 1009 million Swiss Francs in the same year. See http:/www.msf.org/sites/ msf.org/files/msf_financial_report_interactive_2012_final.pdf and http://www.icrc.org/eng/assets/files/annualreport/icrc-annual-report-2012.pdf (July 18, 2013).
} 
practice." Krain (2012) provides macro-quantitative evidence in support of this thesis, showing that public appeals by NGOs, Western media, and IOs have reduced the severity of politicides and genocides. Hendrix and Wong's (2013) analyses of Amnesty International and international media condemnation of human rights abuses partially support this regularity for autocracies, but not for democracies and hybrid regimes. Hafner-Burton's (2008) extensive study on naming and shaming, by contrast, suggests that perpetrating governments often switch from one form of human rights abuse to another one once the global media has put them under the spotlight. Shaming on human rights abuses is done by various actors. An event data analysis examining the role of shaming by international NGOs maintains that condemnations alone are not sufficient but can be effective if combined with domestic pressure and with shaming by IGOs or third party states (Murdie and Davis 2011). As the ICRC has, as indicated, for a long time refrained from relying on public diplomacy, we can expect that its rare appeals to the warring parties are carefully crafted and used as a preventive and deterrent measure.

Despite mixed empirical results, we expect that the instruments of persuasion (i.e., the ICRC's seminars offered on humanitarian law) as well as naming and shaming by the ICRC are related to fewer civilian victims.

H3: IHL dissemination activities of the ICRC and the naming and shaming of the conflict parties reduce the incidence of one-sided violence during armed conflict.

\section{Method and data}

We analyze in this article the ratification of international humanitarian law and the role of the ICRC in relation to atrocities committed against civilians during armed conflict. The research design relies on panel regressions of the incidence of one-sided violence and on detailed time series analyses of the conflicts in Bosnia and Darfur in which the organization resorted quite frequently to naming and shaming. For the dependent variable in the panel studies we used the UCDP data on one-sided violence (Eck and Hultman 2007). Their variable counts the number of civilians killed intentionally and directly by the government forces or by an organized rebel group during armed conflict. Thus our sample is limited to one-sided violence in civil wars for the years from 1989 to 2004 for 72 countries. $^{8}$ We conduct the examination with the logarithm of civilians killed (see also Valentino et al. 2010) and use, as indicated by the Hausman test, fixedeffects regression models with robust standard errors. ${ }^{9}$ In robustness tests we also estimate negative binomial regression models. Furthermore, we test for endogeneity in two-stage least square analyses. Finally, we performed Granger causality tests for two selected conflicts to examine whether or not the public condemnations precede changes in the level of one-sided violence or whether the temporal arrow rather points in the other direction.

\footnotetext{
${ }^{8}$ We drop Rwanda from our regressions as an outlier because of its high number of civilian victims but the results are robust if we include it in the tests. We also excluded the observation accounting for $9 / 11$ as this is an event that does not take place in an internal armed conflict setting.

${ }^{9}$ A modified Wald statistic indicated groupwise heteroskedasticity in the residual of the fixed effects model why we conduct our tests with robust standard errors clustered on the state.
} 
International humanitarian law We will investigate whether the ratification of the Geneva Conventions restrains the conflict parties. The Geneva Conventions and Protocols are a key part of the Law of War with which the signatory states try to regulate warfare. The Geneva conventions provide safeguards for military persons hors de combat, namely detainees, sick, and injured, as well as for civilians. Adopted in 1949, the Geneva Convention IV relates to the protection of civilian persons in time of war and was extended to non-international armed conflicts in an additional protocol to the Geneva Conventions from the year 1977. By now, all states in our sample adopted the GC-IV-1949 but not all ratified the AP-II-1977. We concentrate on the years since ratification of the two treaties but also test the respective dummy variables for whether a state is party. Information about the state parties to the treaties related to IHL is available from the ICRC's website. ${ }^{10}$

Presence and activities of the ICRC In investigating the role of the guardian of IHL more closely, we examine whether the presence of an ICRC delegation in a country at civil war has any restraining impact on the conflict parties. The ICRC is present in many countries with permanent delegations, regional delegations, or missions. ${ }^{11} \mathrm{We}$ only coded as presence if the ICRC had a delegation in a given country in a given year, or if there was headquarter of a regional delegation in the country. ${ }^{12}$ We extracted information from the annual reports of the ICRC (various years). ${ }^{13}$ In addition to the dummy variable of whether the ICRC is present in a given year, we estimated the duration of ICRC presence counting the years since the delegation was opened or since the year that is provided in the annual report for the ICRC as being permanently present. The number of years the ICRC is present in a country serves as instrument in the 2SLS tests.

The ICRC exercises an enormous variety of activities, such as visiting detention centers, establishing contact among families, or providing medical support. Our focus was on activities directly related to the promotion and dissemination of IHL. As part of its dissemination strategy, the ICRC offers presentations and seminars for members of the military and police forces to acquaint them with IHL. It teaches soldiers not to attack and mistreat an enemy fighter hors de combat, medical personnel, and civilians. We coded whether such seminars were offered by the ICRC, and whenever precise numbers were provided in the reports, we counted the number of military and police officers that attended such sessions.

We also analyzed naming and shaming by the ICRC through its public condemnations of all or individual conflict parties. Whereas the ICRC follows a rather strict policy of discretion and only rarely applies the strategy of publicly exposing violators of international norms, there are a few instances where it makes public statements. We

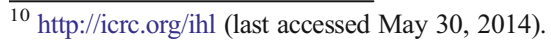

${ }^{11}$ Missions are of a temporary nature and sometimes can be only a trip of a Geneva official to a country to establish first contact. Thus, our analyses do not include these missions.

${ }^{12}$ The regional delegations typically attend to several countries in the region but are not necessarily heavily involved in each state. Besides, the yearly reports do not always distinguish very clearly among the various activities of the regional delegation according to target country. Therefore, we only consider the ICRC as active in a country if the regional delegation had its main office there.

${ }^{13}$ All variables extracted from the ICRC annual reports were coded by two independent coders. The correlation for the presence variable was .88 , for seminars .66 , for participants .73. Divergent cases were individually verified and corrected.
} 
coded actions of condemnations based on ICRC press releases and various news reports. ${ }^{14}$ The events were weighted according to the Goldstein (1992) scale; we distinguish between three levels of severity of condemnations. ${ }^{15}$

As control variables we included the logarithm of population and of real GDP per capita from the Penn World Tables 6.3 (Heston et al. 2009). In populous countries the number of civilians killed presumably is higher, whereas in economically developed countries we can expect fewer civilian casualties (Eck and Hultman 2007). We also control for the type of political regime and its stability with the duration variable from the Polity IV data (Marshall and Jaggers 2002). With the duration variable we can account for whether subsequent political leaders adhere to the ratification of IHL, especially in the face of a political regime change. Duration counts the number of years since the most recent regime change of more than three points on the Polity scale. As the time since ratification could also be related to the length of a state's existence, we also account for the years since independence, based on the Correlates of War's (2008) list on state system membership. Furthermore, we control for the conflict intensity with a variable for the presence of a full-fledged civil war, this means a conflict with more than 1000 battle-related casualties, as differentiated by the UCDP/ PRIO data set on armed conflict (Gleditsch et al. 2002).

We use the individual instances of naming and shaming also for the two illustrative case studies that rely on the KOSVED data set (Schneider and Bussmann 2013) for enabling us to test whether the ICRC reacts to IHL abuses or whether public condemnation reduce the carnage. Like the UCDP data on one-sided violence, the KOSVED data set employs publicly available sources and provides information on individual acts of violence. ${ }^{16}$ It is used for the analysis of the interaction between ICRC and the one-sided violence occurring in conflict areas, and is aggregated at the weekly (Bosnia) and monthly (Darfur) level of temporal aggregation. We resort to vector auto-regression to uncover whether changes in one series precede changes in the other series (Lütkepohl 2005).

\section{Effects of the laws of war and the ICRC activities}

This section examines, with the help of panel and time-series models, the effects of the ratifications of the Law of War and ICRC activities on one-sided violence. The first set of tests, reported in Table 1, refers to the years since ratification of the Geneva Convention IV and the Additional Protocol II and how this relates to the number of civilians killed in civil war. The positive relationship between the number of years since a state party ratified the GC-IV-1949 and one-sided violence, by the government forces

\footnotetext{
${ }^{14}$ We relied on ICRC press releases (only available for 2004) and news reports of Le Monde (who has a permanent correspondent in Geneva), Le Figaro (from 1990 to 2003), New York Times, and BBC Monitoring (1989).

${ }^{15}$ Condemnations in the first category stand for defensive verbal conflict and summarize statements in which the ICRC uses phrases as reject, protest or deny. The middle category stands for offensive verbal conflict, with the organization accusing, demanding, warning or threatening the warring parties. The most intensive action indicates events in which the organization demonstrated or reduced its relationship in the conflict area in response to the actions taken by the conflict parties.

${ }^{16}$ We describe the coding instructions in a related paper (Schneider and Bussmann 2013), which also includes a discussion of the advantages and disadvantages of using newspaper reports for estimating how intensive the political violence is in a particular conflict.
} 
Table 1 Ratification of Geneva convention IV and additional protocol II and one-sided violence

\begin{tabular}{lllll}
\hline & $(1)$ & $(2)$ & $(3)$ & $(4)$ \\
& OSV by government & OSV by rebels & OSV by government & OSV by rebels \\
\hline Log (population) & $7.5423 * *(2.935)$ & $1.5727(3.694)$ & $7.5245 * *(2.957)$ & $1.5650(3.317)$ \\
Log (real GDP pc) & $0.3649(0.603)$ & $-0.3709(0.651)$ & $0.3507(0.597)$ & $-0.2359(0.589)$ \\
Civil War & $0.5493 * * *(0.162)$ & $0.9117 * *(0.338)$ & $0.5507 * * *(0.161)$ & $0.9001 * *(0.366)$ \\
Regime duration & $-0.0437 * *(0.014)$ & $0.0056(0.021)$ & $-0.0442 * *(0.014)$ & $0.0084(0.020)$ \\
Political regime & $-0.0652 *(0.035)$ & $0.0513(0.053)$ & $-0.0654 *(0.034)$ & $0.0534(0.060)$ \\
Independence years & $-0.3158^{* *}(0.134)$ & $-0.1601(0.141)$ & $-0.0902(0.065)$ & $-0.0292(0.114)$ \\
GC-IV-1949 years & $0.2148 * *(0.093)$ & $0.2131 *(0.125)$ & & \\
AP-II-1977 years & & & $-0.0236(0.043)$ & $0.1824 *(0.096)$ \\
Constant & $-61.9787 * *(23.261)$ & $-7.9686(29.329)$ & $-69.2911 * * *(25.782)$ & $-11.1721(26.803)$ \\
Observations & 406 & 406 & 406 & 406 \\
$\mathrm{R}^{2}$ & 0.111 & 0.083 & 0.112 & 0.123 \\
Number of states & 64 & 64 & 64 & 64 \\
\hline
\end{tabular}

Outcome variables are the natural logarithm of victims of one-sided violence by perpetrator. The fixed-effects models were run with STATA 13.0; robust standard robust errors appear in parentheses. $* * * p<0.01, * *$ $p<0.05, * p<0.1$

as well as by the rebel groups, supports our hypothesis. With the passage of time after ratifying the Geneva Convention IV the number of civilian victims increases indicating that obedience of international law might be on the wane. The empirical results lend further support to our hypothesis by showing that the longer ago a state has ratified the AP-II-1977, the more the rebels use violence against civilians during an armed conflict, whereas the variable is not significantly related to one-sided violence committed by the government. In analyses reported in the web appendix available on this journal's website, we added the respective dummy variables for whether a state ratified the treaties. In states that ratified the GC-IV-1949, less one-sided violence is committed by all conflict parties, however, this finding hinges on very few observations as practically all states in our sample ratified the Geneva Convention on the protection of civilians. ${ }^{17}$ The dummy variable for whether a state adopted the additional protocol to extend the Geneva Conventions to civil wars was not significant.

The control variables largely confirm previous findings (Eck and Hultman 2007). In populous countries there are more civilians killed, a relationship that is highly significant for one-sided violence committed by the government but not for atrocities by the rebels. The relationship between GDP per capita and one-sided violence is not significant, albeit with a positive coefficient in the models of government one-sided violence and negative for rebel one-sided violence. In full-fledged civil wars, more one-sided violence is committed by the rebels and the government side. The duration of a political regime is negatively related to the number of civilian victims killed by government forces, a highly significant result. We can also observe less government atrocities in

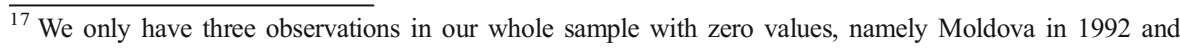
Eritrea in 1997 and 1999 why our tests with the dummy variable for ratification of the GC-IV-1949 will be of limited value only.
} 
more democratic countries. The longer a state is already independent, the less violence against civilians we see, but the finding is only statistically significant in the first model. Both models, violence committed by government forces as well as rebel forces, have a rather poor fit. Especially in the models of government violence most variance is explained by the fixed-effects $($ rho $=.98)$.

The results are largely robust to different model specifications, ${ }^{18}$ such as the inclusion of one-sided violence by the other conflict party to account for reciprocal violence, a variable that is positive and significant but its inclusion does not change our main finding. We also included controls for shaming efforts by international media and by Amnesty International, based on data and findings from Krain (2012). Whereas shaming by international media was not significantly related to one-sided violence, the indicator variables accounting for Amnesty International news reports or background papers were positively related to civilian victimization. While reverse causality might explain the positive coefficients, the inclusion of these various controls did not alter our result on the ratification of the Geneva Convention IV and the Additional Protocol II. Estimations with a two-way fixed effect model including year dummies and a random-effects negative binomial model also confirmed our findings, with the exception that the variable for the years since ratification of the GC-IV-1949 was no longer significantly related to one-sided violence by rebels. ${ }^{19}$ In substantive terms, the results are quite small. Based on the models of Table 1, if a country had ratified the GC-IV-1949 or the AP-II-1977 already 10 years longer we could observe a difference of only 1 or 2 civilian victims. ${ }^{20}$

Altogether, our results support hypothesis 1; the longer ago a state has ratified the Geneva Convention to protect civilians and the additional protocol extending this norm to intra-state wars, the more one-sided violence we can observe indicating that compliance with this international law fades out.

In Table 2, we concentrated more directly on the presence of the ICRC in the conflict states. In the first column, the presence of the ICRC has no statistically significant inhibiting effect on one-sided violence by the government. The presence of the ICRC is also not related to one-sided violence committed by rebel groups (column 2). These results remain statistically insignificant with a negative coefficient in the models of government violence and a positive coefficient in the models of rebel violence in various robustness tests. $^{21}$

\footnotetext{
${ }^{18}$ All test of robustness can be found in the web appendix.

${ }^{19}$ In these tests the control variables in the model on rebel violence were highly significant underlining the importance of estimating with fixed-effects, which is however problematic in the negative-binomial model as too many observations drop out.

${ }^{20}$ If a country had ratified the GC-IV-1949 already 10 years longer we could observe an increase in the log of OSV by the government of 0.3213 (SE 0.1204) which is, after the exponential transformation, the equivalent of 1.37 more civilian victims killed by the government and 0.0342 (SE 0.2073), or 1.03 more civilians killed by the rebels. Having ratified the additional protocol 10 years earlier would be related to a reduction of 0.1000 (SE 0.1879), or 1.10 fewer killings by government forces and a plus of 0.4676 (SE 0.3944), or 1.59 more civilian victims by rebel forces. Calculations of substantive effects are done with Clarify (Tomz et al. 2003). We had to base the estimation on a pooled model as panel estimation is not supported by Clarify. This did change some of the results of the control variables but not the main conclusions on our results for IHL ratification. However, the findings in columns 2 and 4 were no longer significant.

${ }^{21}$ In different model specifications, e.g., controlling for an indicator variable for whether there was one-sided violence by the government in the previous year, controlling for one-sided violence by the rebel side, or for regime transition and collapse, years since independence, and type of political regime, these findings are robust. The ICRC variables show very similar results if estimated with a negative binomial model.
} 


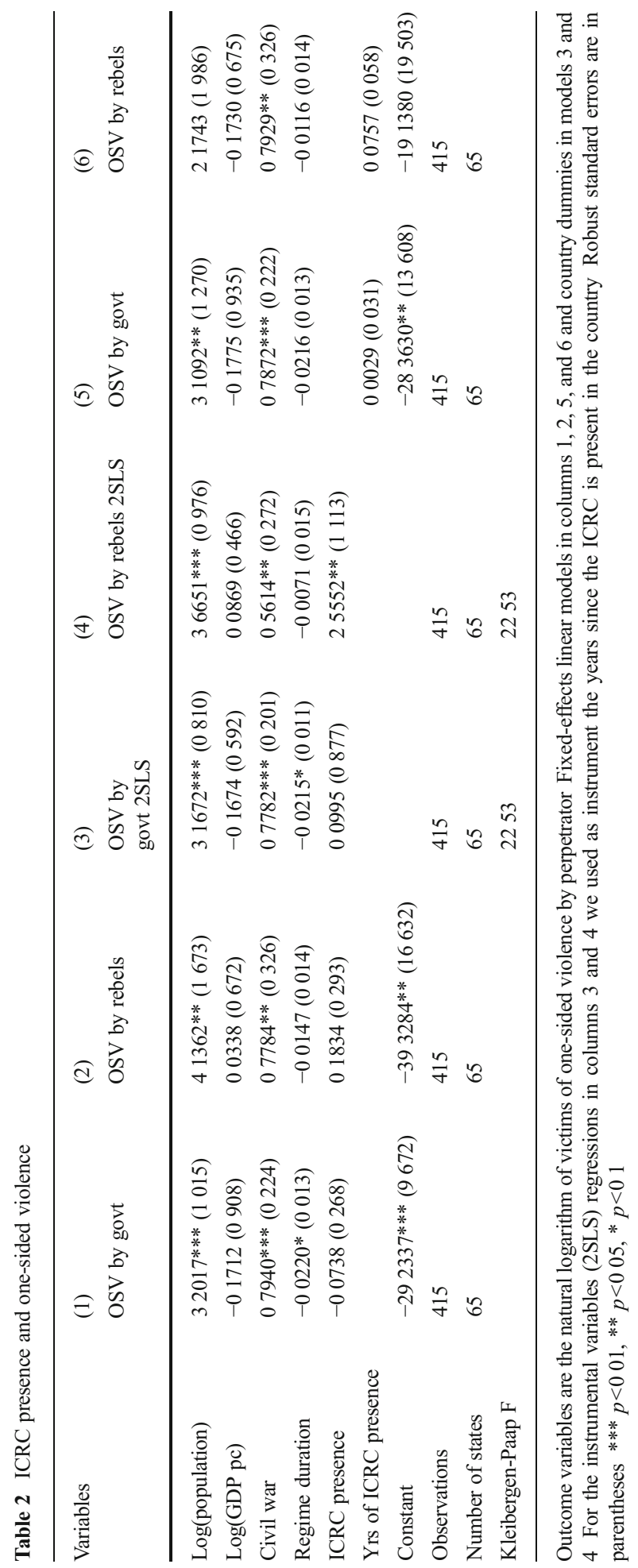


Reverse causality might bias the results as the ICRC is active in conflict zones and might be mostly present in severe conflicts with many civilian victims. We investigate the question of endogeneity in a two-stage least squares (2SLS) approach. The main challenge is to find an appropriate instrument. We conducted the tests with an instrumental variable that accounts for the number of years the ICRC was already present (reported in columns 3 and 4). Organizational processes are slow, and path-dependence marks institutional development (Pierson 2003). As with many other international organizations, we expect a certain persistence and reform inertia of the ICRC, which should, as any other large organization, strive for survival, aim to preserve the status quo and, as such, resist change. Recognizing the need for adaptation, Audet (2011) deplores the organizational immobility of humanitarian actors such as the ICRC. McCalla (1996) attributes this tendency in a case study of NATO to an eagerness to demonstrate that the work undertaken by the organization is necessary and to resist a cut in activities, personnel and resources. For the ICRC this means that the organization has an interest in maintaining its delegations as long as possible. Consequently, we expect that the ICRC is more likely to be present in a country in a given year if it has been there in previous years already. At the same time, we do not expect the ICRC's length of presence to be in any other way than through its current year's presence to be related to one-sided violence. The length of ICRC presence might be related to the duration of a conflict. Previous studies, however, provide mixed results on whether civilian victimization decreases in the course of a conflict (Hultman et al. 2013, Wood et al. 2012). Thus we perform also tests where we replace the civil war dummy variable with the number of years that the conflict had been ongoing as control. The instrument has explanatory power in the first stage as indicated by the Kleibergen-Paap Wald rk F statistic of 22.53 which is above the critical value. ${ }^{22}$ The 2SLS tests of Table 2 indicate that the presence of the ICRC is not related to violence committed against civilians by government forces. In column 4, though, the ICRC presence is even positively and significantly related to one-sided violence by the rebels. While we do not want to put too much emphasis on this positive coefficient without further tests our results indicate that the presence of the ICRC, in any case, is not related to fewer atrocities committed against the civilian population. This finding holds if we control for war duration instead of for the dummy of a full-fledged civil war. In columns 5 and 6 of Table 2, we entered the duration of ICRC presence prior to the conflict year directly to the model and it is not significantly linked to one-sided violence.

We also investigated a number of potential instruments that had been used in the literature on ratification of human rights treaties, such as years of independence (Neumayer 2005), or the origin of the legal systems (Simmons 2009, Gauri 2011, Cole 2012) using data from LaPorta et al. (2008). However, all these instruments turned out to be too weak with the Kleibergen-Paap Wald rk F statistic far below the rule of thumb (see web appendix). Accounting for the peer argument logic (Gauri 2011, Simmons 2009) we assume that if many countries allow the ICRC in, others will see the benefits and also be more open to ICRC presence. Following Cole's (2012) approach to account for global diffusion processes by using the number of countries

\footnotetext{
${ }^{22}$ The 2SLS tests are based on instrumental variable (2sls) estimation using the ivreg 2 command with robust standard errors and country dummies that had to be partialled out to have full rank. All additional test with potential instruments are reported in the web appendix.
} 
worldwide that have ratified a treaty as an instrument, we tested the total number of countries in our sample in which the ICRC is present with a delegation as instrument. This instrument is just slightly below the rule of thumb for the Kleibergen-Paap Wald rk F statistic and the results once more indicate that the presence of the ICRC is not related to fewer civilian victims. We also investigated the presence of the ICRC in neighboring countries only as instrument for ICRC presence assuming that a delegation in close proximity could also attend to a conflict in a neighboring country thus making the ICRC presence less likely which turned out to be too weak. Altogether, we do not find evidence that the ICRC's presence is related to less one-sided violence.

The mere presence only vaguely informs us about the attempts of the ICRC to persuade combatants that they should respect the Geneva conventions. In the analyses reported in Table 3, we therefore refine the tests on ICRC presence by concentrating on ICRC activities that relate specifically to the dissemination of IHL and naming and shaming, two potential mechanisms on how the ICRC might inhibit conflict parties from committing atrocities against civilians during a conflict. ${ }^{23}$ In the first two models we tested specific IHL dissemination activities, namely IHL sessions and seminars that the ICRC conducted among military and police forces. ${ }^{24}$ The findings do not support the hypothesis that spreading knowledge of IHL among military personnel reduces the number of atrocities among civilians. The rare public condemnations by the ICRC also are insignificantly related to one-sided violence (columns 3 and 4). We thus have so far no reason to believe that the instruments of persuasion and public condemnations can reduce civilian suffering.

One could easily object that no effect is visible because of the high-level of temporal aggregation of the data. Hence, a protest by the ICRC could lead to a short-term reduction of the carnage, but not necessarily to an end of the violent campaign itself. We have therefore conducted time series analyses for two conflicts for which we possess such disaggregated data and where the ICRC protested quite frequently. Figures 1 and 2 illustrate with reliance on the KOSVED data how the violence changed during the civil wars in Bosnia and Darfur. The two figures on time series of the total number of civilians and unarmed soldiers killed or harmed during a conflict week (Bosnia) or conflict months (Darfur). As the death toll of the Srebrenica massacre was particularly dramatic, we have log-transformed the casualty numbers for the most violent civil war that has occurred after the dissolution of Yugoslavia.

In the Bosnian civil war, the ICRC voiced 13 times its concerns, 11 times of it quite mildly (reject, protest, deny), once a bit more aggressively (accuse, demand, warn, threaten) and once in the form of a mild conflictive action through a reduction of the relationship. The ICRC did not escalate its condemnations in Darfur much. All 14 events belong to the first and mildest form of negative verbal action. The visual inspection of the figure does not allow a clear conclusion of whether or not these actions had any influence. This is in contrast to the Darfur conflict where the dashed

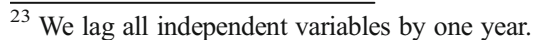

${ }^{24}$ The ICRC conducted seminars in slightly more than half of our observations. We also tested the number of military/police personnel that attended these seminars whenever the respective information was provided in the annual reports. The variable was not significant, neither if estimated as an ordinal five-valued scale (with values from 1 to 5 if $19,1099,100999,10009999$, or 10,000 and more police and/or military personnel attended the IHL seminars).
} 


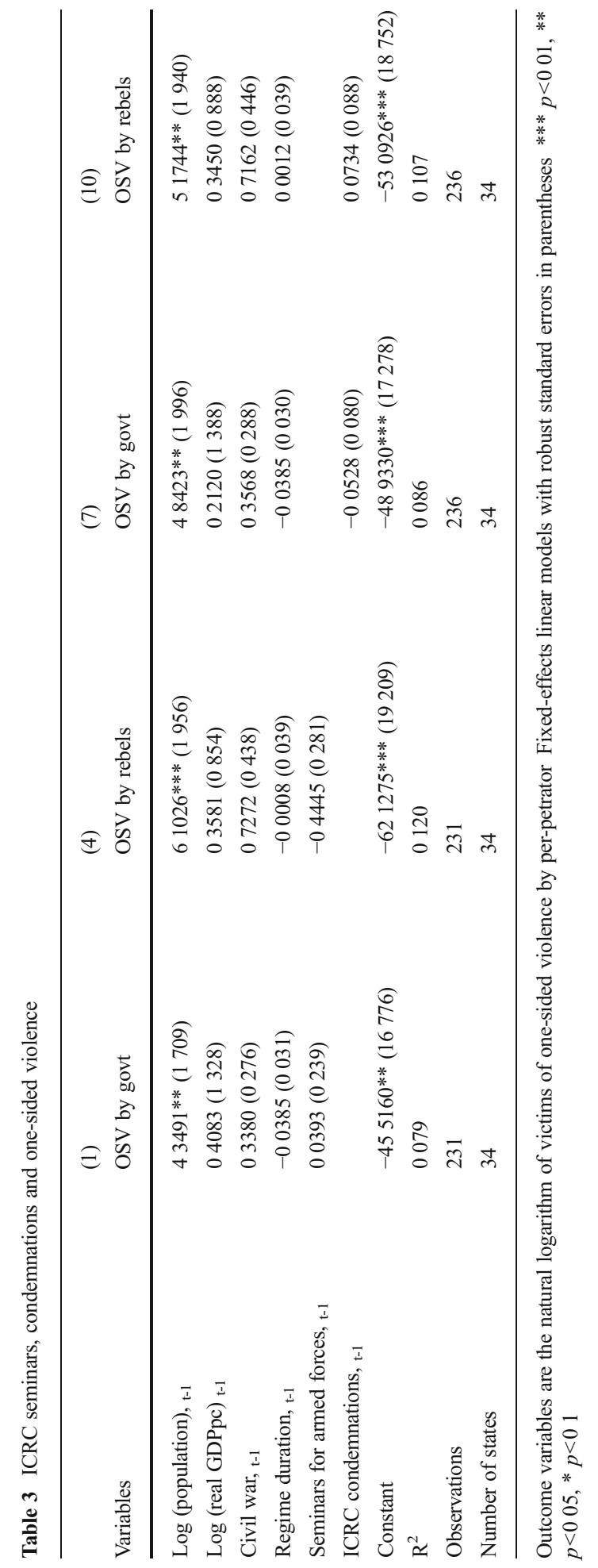




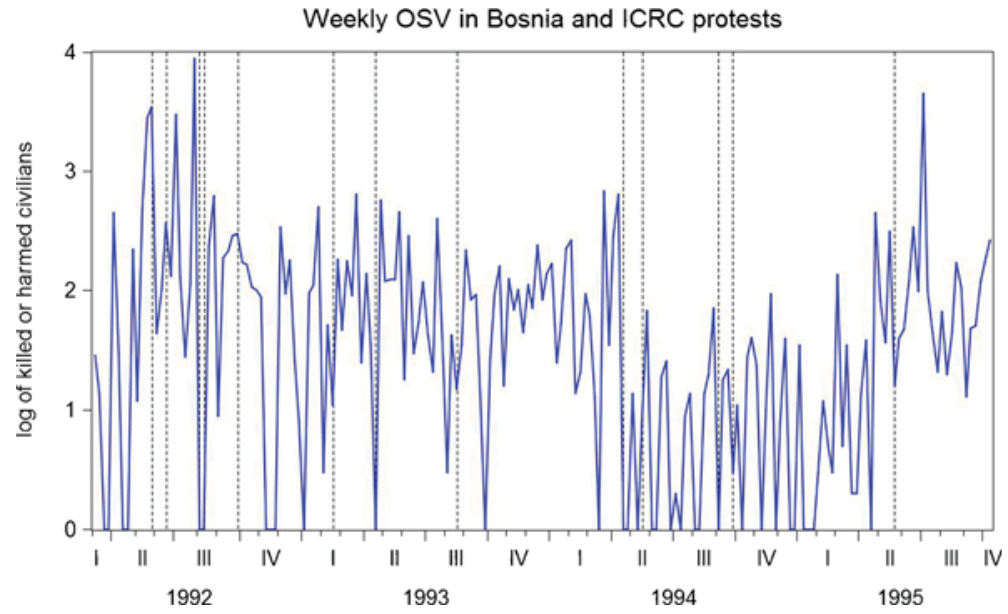

Fig. 1 The log-transformed number of killed and harmed civilians per 'week during the civil war in Bosnia' (Schneider et al. 2012) and the timing of ICRC protests. Note The number of civilians who have fallen victim to one-sided violence is taken from the KOSVED Data Set; for coding details see Schneider and Bussmann (2013). We imputed a value of 0 for the weeks without victims of one-sided violence and indicate the occurrence of ICRC protests through dashed lines. Information on the protests is based on a content analysis of LexisNexis in French and English

lines are often followed by an increase in the violence, indicating the impotence of the organization.

Statistical tests in the form of vector auto-regression allow us to test whether naming and shaming preceded (in technical parlance, Granger caused) changes in the intensity of one-sided violence, or whether the temporal arrow points in the opposite direction. We report these results in Table 4. Note that we use the log of the number of people

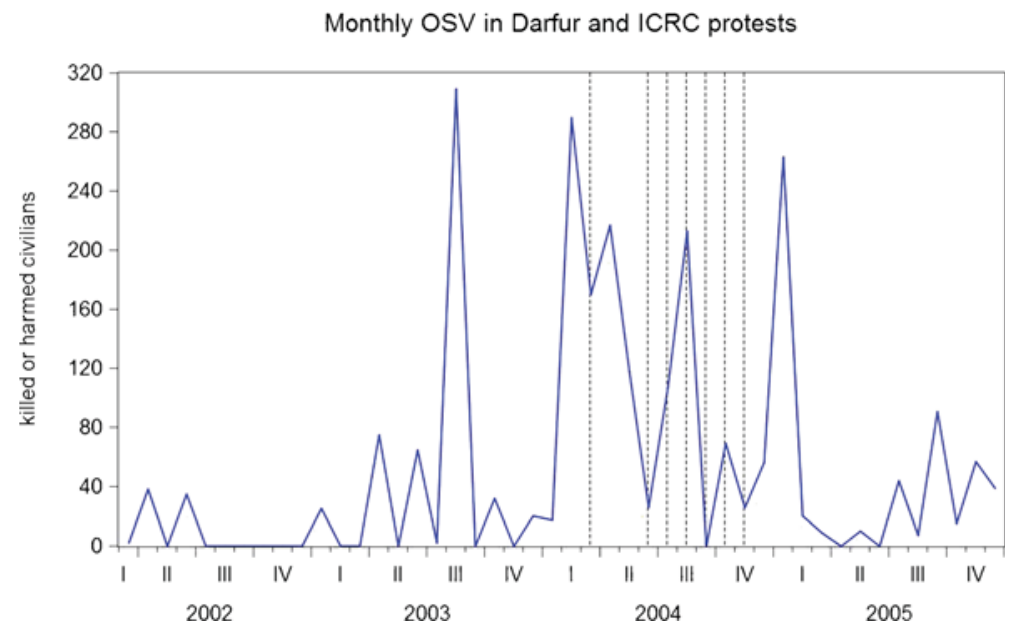

Fig. 2 The number of killed and harmed civilians per month during the civil war in Darfur and the timing of ICRC protests. Note: The number of civilians who have fallen victim to one-sided violence is taken from the KOSVED Data Set (Schneider and Bussmann 2013). We imputed a value of 0 for the month without victims of one-sided violence and indicate the occurrence of ICRC protests through dashed lines. In some months, there were multiple protests. Information on the protests is based on a content analysis of LexisNexis in French and English 
Table 4 ICRC naming and shaming and one-sided violence (Granger causality tests)

\begin{tabular}{llll}
\hline Bosnia & & & \\
Exogenous variable & Restricted coefficient & $\chi^{2}$ & p-value \\
Log(one-sided violence) & ICRC condemnations & 3.12 & 0.21 \\
ICRC condemnations & Log(one-sided violence) & 6.19 & 0.05 \\
Darfur & & & p-value \\
Exogenous variable & Restricted coefficient & $\chi^{2}$ & 0.37 \\
Log(one-sided violence) & ICRC condemnations & 1.99 & 0.13 \\
ICRC condemnations & Log(one-sided violence) & 4.03 & \\
\hline
\end{tabular}

The log of the number of people killed or harmed in a conflict week (Bosnia) and conflict month (Darfur) is used as an outcome variable. The table reports the Granger causality tests for vector auto-regression models with two lags

killed or harmed in a conflict week (Bosnia) and conflict month (Darfur). This difference in the level of aggregation is due to the large number of weeks for which no acts of one-sided violence are reported in the Sudanese war-affected region. ${ }^{25}$

The result of the Granger causality tests support the view that the ICRC was in a reactive rather than proactive role in Bosnia and that the series under consideration are not Granger causally linked to each other for the case of Darfur. The Wald tests show that for the civil war in Ex-Yugoslavia we can reject the null hypothesis of the absence of a temporally causal link. This shows that the casualty figures lead to condemnations and that the opposite does not hold.

\section{Conclusion}

The article offers, to our knowledge, the first systematic evaluation of the impact that the norms advocated by the International Committee of the Red Cross have on the risk of civilians being killed in a conflict. States that have ratified the Geneva Conventions and Protocols are obliged to protect civilians in both interstate and intrastate wars. Our analyses suggest that the norms advocated by the ICRC do not entice military commanders and their combatants to learn that the targeting of civilians is inhumane. The analysis rather suggests that these obligations of the Geneva Conventions and Protocols are rather forgotten over the course of time and hence that no learning can be observed. If anything, our results indicate that the longer the period since the ratification of these norms, the higher the risk of the civilian population. We also found evidence that the training seminars, which are provided by the ICRC, do not have the desired effect and that the presence of an ICRC delegation is not associated with fewer killings. The lacking effect of public condemnations suggests that the naming and shaming that this non-governmental actor possesses as an instrument of deterrence is not sufficiently strong and does not prevent troops both on the government and rebel side from committing atrocities.

\footnotetext{
${ }^{25}$ Similar results to the ones reported in Table 4 could be obtained in Granger causality tests for series in which we used weekly data for Darfur. We also tested different numbers of lags.
} 
The results nevertheless suggest that we should evaluate the role that nongovernmental actors like the ICRC play in the prevention of mass killings much more critically. If the ICRC's presence and seminars do not contribute to more respect for the civilian population, we need to consider how the sanctioning mechanisms related to international humanitarian law can be strengthened. It is in our view indispensable that the ICRC reconsiders its criteria for intervention and condemnation. Research endeavors need to continue scrutinizing the effectiveness of other activities of the ICRC. To be clear, in this study, we only concentrated on the ICRC's role in protecting civilians examining two specific instruments of how the ICRC approaches this problem. There might be other instruments employed but due to the confidential character of the ICRC's negotiations with governments and the organization's overall lack of transparency these mechanisms cannot be scrutinized independently. The ICRC is involved in many other important activities, such as medical relief work and visiting detainees, and compliance might vary across different issues (Jo and Thomson 2014). It is conceivable that the ICRC accepts some sacrifices for the sake of other priorities. Arguments like the one brought forward that public condemnations might endanger access to detainees hint at the importance of issue linkages. However, the effectiveness of possible trade-offs need to be investigated empirically. We can at the moment therefore only conclude that the humanitarian shield through which the ICRC tries to protect the civilian population in endangered areas becomes more and more porous with the years that have passed since it was first put in place. The treaty inheritance problem identified in this article as a factor that limits regime effectiveness is probably also observable elsewhere. We therefore advocate that the compliance literature starts to focus more on the long-term implications of international humanitarian regimes.

Acknowledgments The article has profited from comments by the audiences at several conferences and seminars. We are especially grateful to Kristin Eck, Erik Gartzke, Michaela Mattes, and Winfried Pohlmeier as well as the editor and two anonymous reviewers for detailed recommendations. We would also like to thank the Deutsche Stiftung Friedensforschung for supporting our research under grant DSF 004/07 and Isabel Schneider, Romy Escher, Sebastian Kuhn, Marina Beielstein, Kristof Lintz, Ivo Sieder and Oliver Neumann for research assistance, and the ICRC for access to its library resources and a discussion with ICRC collaborator Dominique Loye about our results.

\section{References}

Audet, F. (2011). L'acteur humanitaire en crise existentielle : Les défis du nouvel espace humanitaire. Études Internationales, 42(4), 447472.

Axelrod, R. (1984). The evolution of cooperation. New York: Basic Books.

Balmer, D. (1984). Grünspan. Mensch und Humanität. Zürich: Abedul.

Ben-Tov, A. (1990). Das Rote Kreuz kam zu spät. Zürich: Amman.

Bercovitch, J., \& Schneider, G. (2000). Who mediates? The political economy of international conflict management. Journal of Peace Research, 37(2), 145165.

Branch, A. (2009). Humanitarianism, violence, and the camp in northern Uganda. Civil Wars, 11(4), 477501.

Bugnion, F. (2000). Le Comité International de la Croix-Rouge et la protection des victimes de la guerre. Geneva: Comité Internationale de la Croix-Rouge.

Cole, W. M. (2012). Human rights as myth and ceremony? Reevaluating the effectiveness of human rights treaties, 1981 2007. American Journal of Sociology, 117(4), 11311171.

Correlates of War Project. (2008). State system membership list, v2008.1. http://correlatesofwar.org. Accessed 19 Aug 2015. 
Delorenzi, S. (1999). Contending with the impasse in international humanitarian law. Geneva: International Committee of the Red Cross.

DeMeritt, J. H. R. (2012). International organizations and government killing: Does naming and shaming save lives? International Interactions, 38(5), 597621.

Downes, A. B. (2008). Targeting civilians in war. Ithaca: Cornell University Press.

Eck, K., \& Hultman, L. (2007). One-sided violence against civilians in war: Insights from new fatality data. Journal of Peace Research, 44(2), 233246.

Fast, L. A. (2007). Characteristics, context and risk: NGO insecurity in conflict zones. Disasters, $31(2), 130154$

Fast, L. A. (2010). Mind the gap: Documenting and explaining violence against aid workers. European Journal of International Relations, 16(3), 365389.

Favez, J.-C. (1988). Une mission impossible? Le CICR, les déportations et les camps de concentration nazi. Lausanne: Éditions Payot.

Finnemore, M. (1993). International organization as teachers of norms: The United Nations educational, scientific, and cultural organization and science policy. International Organization, 47(4), 565597.

Finnemore, M. (1996). National interests in international society. Ithaca, NY: Cornell University Press.

Finnemore, M., \& Sikkink, K. (1998). International norm dynamics and political change. International Organization, 52(4), 887917.

Forsythe, D. P. (2005). The humanitarians: The International Committee of the Red Cross. Cambridge: Cambridge University Press.

Gauri, V. (2011). The cost of complying with human rights treaties: The convention on the rights of the child and basic immunization. Review of International Organizations, 6(1), 3356.

Gilligan, M. J. (2006). Is enforcement necessary for effectiveness? A model of the international criminal regime. International Organization, 60(4), 935976.

Gleditsch, N. P., Wallensteen, P., Eriksson, M., Sollenberg, M., \& Strand, H. (2002). Armed conflict 1946 2001: A new dataset. Journal of Peace Research, 39(5), 615637.

Goldstein, J. S. (1992). A conflict-cooperation scale for WEIS events data. Journal of Conflict Resolution, $36(3), 369385$

Goodman, R., \& Jinks, D. (2004). How to influence states: Socialization and international human rights law. Duke Law Journal, 54(3), 621703.

Hafner-Burton, E. M. (2005). Trading human rights: How preferential trade agreements influence government repression. International Organization, 59(3), 593629.

Hafner-Burton, E. M. (2008). Sticks and stones: Naming and shaming the human rights enforcement problem. International Organization, 62(4), 689716.

Hafner-Burton, E. M. (2009). Forced to be good. Why trade agreements boost human rights. Ithaca: Cornell University Press.

Hafner-Burton, E. M., \& Tsutsui, K. (2007). Justice lost! The failure of international human rights law to matter where needed most. Journal of Peace Research, 44(4), 407425.

Hathaway, O. A. (2007). Why do countries commit to human rights treaties? Journal of Conflict Resolution, $51(4), 588621$.

Hendrix, C. S., \& Wong, W. H. (2013). When is the pen truly mighty? Regime type and the efficacy of naming and shaming in curbing human rights abuses. British Journal of Political Science, 43(3), 651672.

Heston, A., Summers, R., \& Aten, B. (2009). Penn World Table Version 6.3, Center for International Comparisons of Production, Income and Prices: University of Pennsylvania.

Hultman, L. (2010). Keeping peace or spurring Violence? Unintended effects of peace operations on violence against civilians. Civil Wars, 12(1\&2), 2946.

Hultman, L., Kathman, J., \& Shannon, M. (2013). United Nations peacekeeping and civilian protection in civil war. American Journal of Political Science, 57(4), 875891.

International Committee of the Red Cross (2009). Annual Report 2008. Geneva: ICRC.

Jo, H., \& Thomson, C. P. (2014). Legitimacy and compliance with international law: Access to detainees in civil conflicts, 1991 2006. British Journal of Political Science, 44(2), 323355.

Kalyvas, S. N. (2006). The logic of violence in civil war. Cambridge: Cambridge University Press.

Kellenberger, J. (2004). Speaking out or remaining silent in humanitarian work. Revue Internationale de la Croix Rouge/International Review of the Red Cross, 86(855), 593609.

Krain, M. (2005). International intervention and the severity of genocides and politicides. International Studies Quarterly, 49(3), 363387.

Krain, M. (2012). J'accuse! Does naming and shaming perpetrators reduce the severity of genocides or politicides? International Studies Quarterly, 56(3), 574589. 
$\mathrm{Ku}, \mathrm{C} .$, \& Brun, J. C. (2003). Neutrality and the ICRC contribution to contemporary humanitarian operations. International Peacekeeping, 10(1), 5672.

Kuperman, A. J. (2001). The limits of humanitarian interventions: Genocide in Rwanda. Washington D.C.: Brookings Institution Press.

Kydd, A. (2003). Which side are you on? Bias, credibility and mediation. American Journal of Political Science, 47(4), 597611.

Kydland, F. E., \& Prescott, E. C. (1977). Rules rather than discretion: The inconsistency of optimal plans. The Journal of Political Economy, 85(3), 473492.

LaPorta, R., Lopez-de-Silanes, F., \& Shleifer, A. (2008). The economic consequences of legal origins. Journal of Economic Literature, 46(2), 285332.

Lütkepohl, H. (2005). New introduction to multiple time series analysis. Berlin: Springer.

Marshall, M. G., \& Jaggers, K. (2002). Polity IV dataset. Center for International Development and Conflict Management, University of Maryland.

McCalla, R. B. (1996). NATO's persistence after the Cold War. International Organization, 50(3), 445475.

Meernik, J., Nichols, A., \& King, K. L. (2010). The impact of international tribunals and domestic trials on peace and human rights after civil war. International Studies Perspectives, 11(4), 309334.

Moravcsik, A. (1995). Explaining international human rights regimes. European Journal of International Relations, 1(2), 157189.

Morrow, J. D. (2007). When do states follow the laws of war? American Political Science Review, 101(3), 559572.

Morrow, J. D. (2014). Order within anarchy. The laws of war as an international institution. Cambridge: Cambridge University Press.

Murdie, A. M., \& Davis, D. R. (2011). Shaming and blaming: Using event data to assess the impact of human rights in INGOs. International Studies Quarterly, 56(1), 116.

Murdie, A., \& Peksen, D. (2014). The impact of human rights INGO shaming on humanitarian interventions. Journal of Politics, 76(1), 215228.

Neumayer, E. (2005). Do international human rights treaties improve respect for human rights? Journal of Conflict Resolution, 49(6), 925953.

Pierson, P. (2003). Politics in time: history, institutions, and social analysis. Princeton: Princeton University Press.

Risse, T., Ropp, S. C., \& Sikkink, K. (Eds.). (1999). The power of human rights. International norms and domestic change. Cambridge: Cambridge University Press.

Schneider, G., \& Bussmann, M. (2013). Accounting for the dynamics of one-sided violence: Introducing KOSVED. Journal of Peace Research, 50(5), 635644.

Schneider, G., Bussmann, M., \& Ruhe, C. (2012). The dynamics of mass killings: Testing time-series models of one-sided violence in the Bosnian civil war. International Interactions, 38(4), 443461.

Simmons, B. A. (2009). Mobilizing for human rights: international law in domestic politics. Cambridge: Cambridge University Press.

Simmons, B. (2010). Treaty compliance and violation. Annual Review of Political Science, 13, 273296

Tomz, M., Wittenberg, J., \& King, G. (2003). CLARIFY: Software for interpreting and presenting statistical results. Version 2.1. Stanford University, University of Wisconsin, and Harvard University. http://gking. harvard.edu/.

Valentino, B. A. (2004). Final solutions: mass killing and genocide in the 20th century. Ithaca: Cornell University Press.

Valentino, B. A., Huth, P. K., \& Croco, S. E. (2010). Bear any burden? How democracies minimize the costs of war. Journal of Politics, 72(2), 528544

Weinstein, J. M. (2007). Inside rebellion: the politics of insurgent violence. Cambridge: Cambridge University Press.

Wood, R. M., Kathman, J. D., \& Gent, S. E. (2012). Armed intervention and civilian victimization in intrastate conflicts. Journal of Peace Research, 49(5), 647660.

Young, O. R. (1967). Intermediaries: third parties in international crises. Princeton: Princeton University Press. 